\title{
Skilled Versus Unskilled Assistance in Home Delivery: Maternal Complications, Stillbirth and Neonatal Death in Indonesia
}

\author{
Fase Badriah $^{1 *}$, Takeru Abe $^{2}$, Baequni $^{1,3}$ and Akihito Hagihara ${ }^{3}$ \\ ${ }^{1}$ Syarif Hidayatullah Islamic State University, Faculty of Medicine and Health Sciences, Department of Public Health, Indonesia \\ ${ }^{2}$ Waseda University, Faculty of Human Sciences, Department of Health Sciences and Social Welfare, Saitama, Japan \\ ${ }^{3}$ Osaka University, School of Human Science, Department of International Collaboration, Osaka, Japan \\ ${ }^{4}$ Kyushu University, Graduate School of Medicine, Department of Health Services, Management and Policy, Fukuoka, Japan.
}

*Corresponding author: Fase Badriah, Department of Public Health, Faculty of Medicine and Health Sciences, Syarief Hidayatullah State Islamic University (UIN) Jalan Kertamukti nomor 9, Pisangan, Ciputat, Jakarta, Indonesia, 15419; Tel: +6221-747-16-718; fax: +6221-740-21-16; E-mail: fase_bzm@uinjkt.ac.id

Received date: Jul 24, 2014, Accepted date: Sep 11, 2014, Publication date: Sep 15, 2014

Copyright: $\odot 2014$ Badriah F, et al. This is an open-access article distributed under the terms of the Creative Commons Attribution License, which permits unrestricted use, distribution, and reproduction in any medium, provided the original author and source are credited.

\begin{abstract}
The purpose of this study was to compare adverse intra-partum and post-partum outcomes for home deliveries with skilled and unskilled birth assistance. A cross-sectional study examined Indonesia Demographic Health Survey (IDHS 2007) data for 3,811 ever-married women who had had home deliveries in 2006 and 2007. A logistic regression analysis was used to examine associations between type of assistance at delivery and outcomes. This study found that there was a significantly higher probability of adverse outcomes with skilled assistance than with unskilled assistance for complications at birth and for complications after giving birth. Home deliveries with skilled assistance are not free from the risks of maternal morbidity and neonatal death. This finding raises doubts about the impact of skilled birth assistance. These results call for appropriate training to manage complications during and after childbirth by home delivery using skilled birth assistance. Further research is required.
\end{abstract}

Keywords: Indonesia; Maternal complications; Stillbirth; Home delivery; Assistance at delivery

\section{Introduction}

Unskilled health workers, or "traditional birth attendants" (TBAs), have been suggested as a cause of maternal mortality and undesired neonatal outcomes in home deliveries. In response to the high proportion of home deliveries without skilled assistance and to improve access to professional care at birth as a means of reducing child and maternal mortality, the Indonesian Ministry of Health began placing midwives in villages [1]. In addition, apart from enhancing the awareness, understanding, and appreciation of Millennium Development Goal (MDG) 5 in Indonesia, by 1996 more than 50,000 village midwives had been placed in villages around the country to support progress towards achieving the MDGs related to improving maternal and child health.

This intervention increased the proportion of deliveries attended by skilled assistants from 43\% in 1997 [2] to $79 \%$ in 2007 [3]. However, previous research on local healthcare in rural villages has reported on the quality of care provided by skilled assistants $[3,4]$ and has found that increasing the rate of skilled assistance at delivery did not reduce the maternal mortality rate or maternal morbidity $[4,5]$.

Other studies reported that skilled delivery was not associated with reduced neonatal-maternal mortality overall, but there were interaction effects with geographic region [6-8]. Very few studies have reported associations between type of assistance and outcomes for home delivery after increasing the proportion of skilled assistants. The aim of the present study was to compare outcomes for home deliveries using skilled birth assistance (midwives) with outcomes using unskilled birth assistance (UBA). The outcomes included complications at birth, stillbirths and neonatal outcomes.

\section{Methods}

\section{Data}

We used data from the 2007 Indonesia Demographic and Health Survey (IDHS), a survey conducted periodically to evaluate demographic and health situations in Indonesia. The survey is designed to provide nationally representative information on demographics and maternal and child health in Indonesia. It has been administered as part of the global MEASURE DHS (Demographic and Health Surveys) program [9]. The IDHS recode consisted of IDBR51SV (Birth Recode), IDCR51SV (Couple's Recode), IDHR51SV (Household Recode), IDKR51SV (Children's Recode), IDMR51SV (Male Recode), and IDPR52SV (Household Member Recode). This program was implemented by ICF International in Calverton, Maryland, in partnership with the Johns Hopkins Bloomberg School of Public Health [9].

\section{Study design and sample}

This research was a cross-sectional study examining the type of delivery assistance (skilled or unskilled). The data set has one record for every child ever born to an interviewed woman. It contains the full history of all women interviewed, including information on pregnancy, postnatal care, immunization, and healthcare for every child born in the last 5 years. To minimize recall bias, we selected sample data on all babies born within 2 years of the survey (2006 and 2007) and their mothers. The total number of babies was 7,509. 
Citation: Badriah F, Abe T, Baequni B, Hagihara A (2014) Skilled Versus Unskilled Assistance in Home Delivery: Maternal Complications, Stillbirth and Neonatal Death in Indonesia. J Nurs Care 3: 198. doi:10.4172/2167-1168.1000198

Page 2 of 6

We excluded babies born at health facilities $(3,305)$ because this study aimed to examine home delivery. We excluded twin births $(68$ babies, 1.6\%), babies who required medical doctors for delivery assistance (18 babies, $0.4 \%$ ), babies who required nurses for delivery assistance (73 babies or $1.7 \%)$, and records with missing values (235 babies, 5.6\%). The study excluded medical doctors as delivery assistants because generally in Indonesia most mothers who use medical doctors for home deliveries have a known higher risk at birth, and medical doctors are generally recommended for births at health facilities. This study excluded nurses used as delivery assistance because the number was small $(1.7 \%)$ and because this study was focused on evaluating Indonesia's policy of placing midwives in villages around the country to increase the proportion of health professionals as delivery assistants. We also excluded twin births because these births might involve higher risks for low birth weight and a higher infant mortality rate [10]. Finally, 3,811 home deliveries were analyzed further (Figure 1).

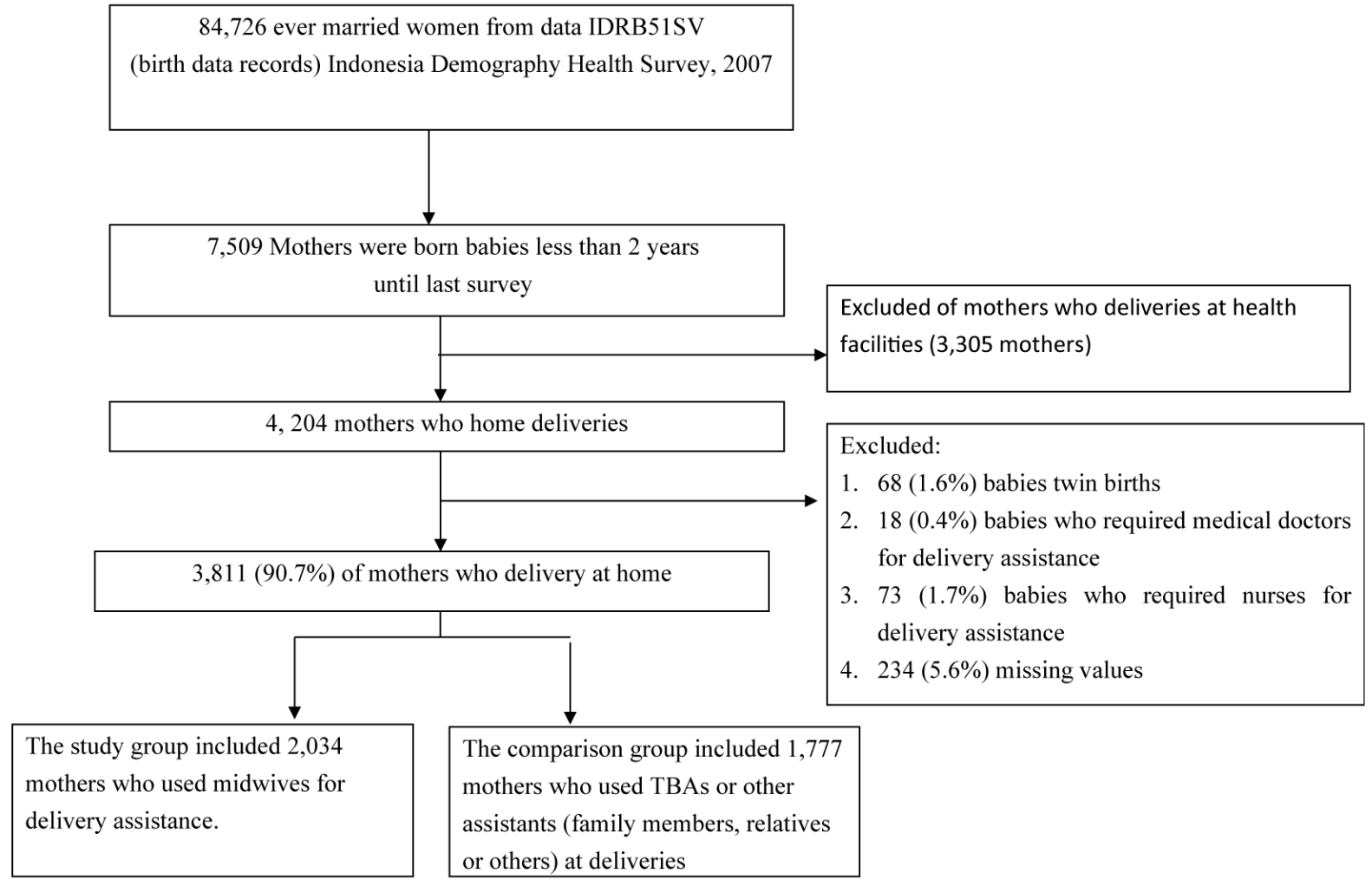

Figure1: Data selection and flow diagram.

\section{Study variables}

The independent variable was the categorical variable type of delivery assistance (skilled assistance or UBA). Skilled assistance included delivery assistance by a village midwife, a local midwife, or any midwife. UBA included delivery assistance by a TBA, a relative, or a family member.

Mothers' characteristics and prenatal healthcare services during pregnancy were confounding variables for maternal and neonatal outcomes. They were included in the analysis as independent variables. Independent variables included socio-demographic factors (wealth index, which originally had five categories that were then reduced to three for the analysis; type of residence, categorized into urban and rural; and mother's education level), mothers' characteristics (the mother's age at the time of the infant's birth; parity; and complications during pregnancy, such as vaginal bleeding, fever, and convulsions; prenatal healthcare during pregnancy; and tetanus vaccine injection before birth [9].
Maternal outcomes included complications at the time of birth and complications after birth (Figure 2). The variable covering delivery complications was based on four types of obstetric complications reported by mothers: prolonged labor (referring to strong and regular contractions lasting more than 1 day and 1 night), excessive vaginal bleeding that soaked more than three pieces of cloth, high fever and foul-smelling vaginal discharge, and convulsions with loss of consciousness $[9,11]$. Most maternal morbidity and mortality is due to direct obstetric complications that occur during labor and after birth [12]. Stillbirths and neonatal deaths were used because the WHO reported an association between birth attendants and stillbirth and neonatal death [13-15]. Stillbirth is the birth of a baby that shows no sign of life at birth (fetal death). We used two variables for neonatal death: neonatal death (death occurring 1-28 days after live birth) and early neonatal death (death during the first 7 days of life) [16]. 
Citation: Badriah F, Abe T, Baequni B, Hagihara A (2014) Skilled Versus Unskilled Assistance in Home Delivery: Maternal Complications, Stillbirth and Neonatal Death in Indonesia. J Nurs Care 3: 198. doi:10.4172/2167-1168.1000198

Page 3 of 6

\begin{tabular}{|c|c|c|c|}
\hline Outcomes & & $\begin{array}{l}\text { Odds } \\
\text { Ratio }\end{array}$ & $(95 \% \mathrm{Cl})$ \\
\hline \multirow{4}{*}{$\begin{array}{l}\text { Complication } \\
\text { at birth }\end{array}$} & Prolonged labor & 1.68 & $(1.45-1.95)$ \\
\hline & Excessive vaginal bleeding & 1.16 & $(0.90-1.47)$ \\
\hline & $\begin{array}{l}\text { Fever and foul smelling vaginal } \\
\text { discharge }\end{array}$ & 1.25 & $(0.96-1.63)$ \\
\hline & Convulsion & 1.13 & $(0.74-1.72)$ \\
\hline \multirow{4}{*}{$\begin{array}{l}\text { Complication } \\
\text { after birth }\end{array}$} & Excessive bleeding & 1.18 & $(0.98-1.41)$ \\
\hline & Convulsion & 1.23 & $(0.79-1.92)$ \\
\hline & Faint & 0.71 & $(0.41-1.23)$ \\
\hline & Fever & 1.35 & $(1.02-1.79)$ \\
\hline
\end{tabular}

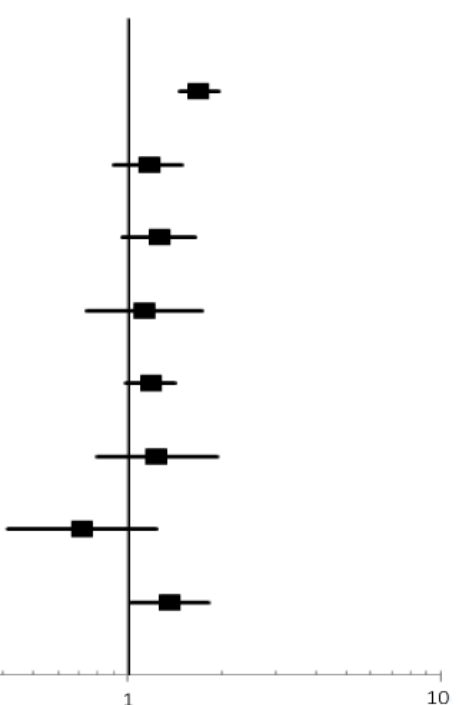

Figure 2: Parameter estimate (odds ratio and 95\% CI) of conditional logistic regression analyses complication at birth and after birth comparing skilled versus unskilled delivery assistants.

\section{Statistical methods}

To describe the characteristics of the mothers and prenatal care during pregnancy, we performed an analysis of frequency tabulations of all variables. We used a crude odds ratio (OR) and an adjusted odds ratio with a $95 \%$ confidence interval (CI) to investigate the estimated associations [17]. First, we used a crude model that considered how the independent variable (type of assistance at delivery) influenced all outcomes. Second, we used an adjusted model that considered how all independent variables influenced these outcomes.

We used logistic regression analyses to determine whether there was any significant association between the outcomes and the independent variable. All p-values reported are two-sided. A p-value less than 0.05 was considered to indicate statistical significance. Data analysis was conducted using SPSS software (ver. 18.0 for Windows; SPSS, Inc., Chicago, IL, USA).

\section{Results}

Almost half of all mothers used skilled birth assistance (53.4\%), and the other half used UBA (46.6\%) for home deliveries. Characteristics and maternal health care differed significantly between mothers using skilled assistance and UBA, except for complications during pregnancy $(\mathrm{p}=0.713)$ and sex of the baby $(\mathrm{p}=0.599)$ (Table 1$)$. These results did not support the assumption that a person with a risk of complications during pregnancy would benefit from skilled assistance rather than UBA.

\begin{tabular}{|c|c|c|c|}
\hline Variables & $\begin{array}{l}\text { Skilled } \\
(n=2,034)\end{array}$ & Unskilled assistance $(n=1,777)$ & $P$ value \\
\hline \multicolumn{4}{|c|}{ Mother's Characteristic } \\
\hline Wealth index & & & $P<0.001$ \\
\hline Poorer & $1,165(30.57)$ & $1,416(37.15)$ & \\
\hline Middle to richer & $869(22.80)$ & $361(9.47)$ & \\
\hline Residence & & & $P<0.001$ \\
\hline Urban & $531(13.93)$ & $274(7.18)$ & \\
\hline Rural & $1,503(39.43)$ & $1,503(39.44)$ & \\
\hline Mother's education & & & $P<0.001$ \\
\hline Primary or less & $826(21.67)$ & $1,183(31.04)$ & \\
\hline secondary or higher & $1,208(31.69)$ & $594(15.59)$ & \\
\hline
\end{tabular}


Citation: Badriah F, Abe T, Baequni B, Hagihara A (2014) Skilled Versus Unskilled Assistance in Home Delivery: Maternal Complications, Stillbirth and Neonatal Death in Indonesia. J Nurs Care 3: 198. doi:10.4172/2167-1168.1000198

Page 4 of 6

\begin{tabular}{|c|c|c|c|}
\hline Mother's age at child birth & & & $P<0.001$ \\
\hline Older (more than 35 year-old) & 191(5.01) & 234(6.14) & \\
\hline Adult ( $25-35$ year-old) & $1,057(27.73)$ & $842(22.09)$ & \\
\hline Young mother $(<25$ year-old $)$ & $786(20.62)$ & $701(18.39)$ & \\
\hline Birth-order number & & & $P<0.001$ \\
\hline First born & $676(17.73)$ & $425(11.15)$ & \\
\hline 2nd-3rd born & $969(25.42)$ & $775(20.33)$ & \\
\hline$\geq 4$ th born & $389(25.42)$ & $577(15.14)$ & \\
\hline Parity & & & $P<0.001$ \\
\hline High, $\geq 4$ times & 199(5.22) & $368(9.65)$ & \\
\hline Low, $<4$ times & $1,835(48.15)$ & $1,409(36.97)$ & \\
\hline \multicolumn{4}{|l|}{ Maternal health care and condition } \\
\hline Tetanus injection before birth & & & $P<0.001$ \\
\hline Yes & $1,489(39.07)$ & $1,007(26.42)$ & \\
\hline No & $545(14.30)$ & $770(20.20)$ & \\
\hline Prenatal care & & & $P<0.001$ \\
\hline No & $1,057(27.73)$ & $1,095(28.73)$ & \\
\hline Yes, professional health & $977(25.63)$ & $682(17.89)$ & \\
\hline Complications during pregnancy & & & 0.713 \\
\hline Yes & $175(4.59)$ & $147(3.86)$ & \\
\hline No & $1859(48.7)$ & $1630(42.77)$ & \\
\hline Child Gender & & & 0.599 \\
\hline Female & $951(24.95)$ & $846(22.20)$ & \\
\hline Male & $1,083(28.42)$ & $931(24.43)$ & \\
\hline
\end{tabular}

Table 1: Mother's characteristics and maternal health care.

In terms of maternal outcomes, the mothers who used skilled assistance during delivery experienced more complications at the time of the birth (48.8\%) compared with mothers who used UBA $(36.3 \%)$. Compared with UBA, skilled delivery was associated with a $75 \%$ increase (adjusted $\mathrm{OR}=1.75$ ) in the probability of complications at birth after controlling for other confounding variables. More complications after birth were also found among women who had skilled assistance (15.9\%) compared with mothers who had UBA (9.83\%). In addition, compared with UBA, skilled assistance was associated with a $59 \%$ increase (adjusted $\mathrm{OR}=1.59$ ) in the probability of complications after birth after controlling for other confounding variables (Table 2).

\begin{tabular}{|l|l|l|l|l|l|}
\hline End point & & & \multicolumn{2}{l|}{ Odds ratio/ 95\% Cl } \\
\hline & Total sample & Skilled & $\begin{array}{l}\text { Unskilled } \\
\text { assistance }\end{array}$ & Crude & Adjusted $^{*}$ \\
\hline Maternal complication & & & & & \\
\hline Complications at birth & $43.0(/ 3811)$ & $48.8(994 / 2,034)$ & $36.3(646 / 1,777)$ & $1.67(1.47 \text { to } 1.91)^{*}$ & $1.75(1.52 \text { to } 2.02)^{*}$ \\
\hline Complications after birth & $25.8(2497 / 3811)$ & $15.9(608 / 2,034)$ & $9.83(375 / 1,777)$ & $1.73(1.50 \text { to } 1.99)^{*}$ & $1.59(1.37 \text { to } 1.85)^{*}$ \\
\hline Neonatal outcomes & & & & & \\
\hline
\end{tabular}




\begin{tabular}{|l|l|l|l|l|l|}
\hline Stillbirths & $0,7(27 / 3811)$ & $0.4(17 / 2,034)$ & $0.3(10 / 1,777)$ & $1.49(0.68$ to 3.26$)$ & $2.17(0.92$ to 5.09$)$ \\
\hline Neonatal death (excluding stillbirths) & & & & & \\
\hline $1-7$ days & $1.0(39 / 3811)$ & $0.4(15 / 2,034)$ & $0.6(24 / 1,777)$ & $0.54(0.28$ to 1.04$)$ & $0.73(0.36$ to 1.47$)$ \\
\hline $1-28$ days & $1.3(82 / 3811)$ & $0.5(21 / 2,034)$ & $0.7(28 / 1,777)$ & $0.65(0.37$ to 1.15$)$ & $0.93(0.50$ to 1.74$)$ \\
\hline
\end{tabular}

Table 2: Numbers and percentages of maternal-neonatal outcomes and parameter estimate (crude-adjusted odds ratios $95 \%$ confidence interval) of regression logistic analyses. ${ }^{*}$ Analyses were adjusted for variable in table $1 ;{ }^{* *} \mathrm{P}$ value $<0.00$.

Among complications at birth, compared with UBA, skilled assistance was associated with a $68 \%$ increase (adjusted $\mathrm{OR}=1.68$ ) in the probability of prolonged labor after controlling for other confounding variables. Among complications after birth, compared with UBA, skilled assistance was associated with a $35 \%$ increase (adjusted $\mathrm{OR}=1.35$ ) in the probability of fever after controlling for other confounding variables (Figure 2).

There was no significant difference between skilled assistance and UBA in terms of stillbirth. In addition, there were no statistically different outcomes in terms of neonatal death between mothers who used midwives and those who used UBA (Table 2).

These findings do not align with the general belief that skilled birth assistance can mitigate adverse outcomes. Compared with UBA, skilled delivery was associated with an increase in the probability of complications at birth (prolonged labor) and after birth (fever). Moreover, compared with UBA, skilled assistance yielded no significantly different outcomes for stillbirth and neonatal death.

\section{Discussion}

Our findings for complications at birth and after birth raise doubts about the impact of skilled birth assistance (alone) on maternal outcomes at delivery. These findings may be attributable to the fact that the skilled assistants were placed in the community rather recently, and were thus well-educated but less experienced at managing prolonged labor at birth and fever after birth by home delivery.

Our results may have several causes. The first is the competency of skilled birth assistants for normal birth assistance. The WHO defines a skilled birth assistant as someone "trained to proficiency in the skills needed to manage normal (uncomplicated) pregnancies, childbirth and the immediate postnatal period, and in the identification, management and referral of complications in women and newborns" [18]. The skilled assistants might not have been ready to provide assistance because they lacked tool kits for home delivery. Most midwives might have spent less time in the village compared with those who provided UBA, who were more experienced and lived permanently in the village $[3,19]$.

Home deliveries that use skilled assistance are not free from the risk of death. Mothers and babies are especially vulnerable to death; a woman with postpartum hemorrhage or a baby with birth asphyxia, sepsis, or complications from preterm birth can die within hours or even minutes if the appropriate care is not provided. Complications during childbirth are often unexpected.

We found significant differences between the two groups in parity and birth number. There were more first-time births and mothers with parity $>4$ among skilled assistance deliveries. This suggests that maternal parity might also have had an impact on the adverse outcomes. Specifically, it might have triggered prolonged labor for women with first-time births and excessive bleeding for mothers with parity $>4$. We found that mothers with high parity were more likely to choose skilled assistance. This finding calls for appropriate training of skilled assistants to recognize when a birth is high risk and not normal, a plan for timely transfer, emergency skills to reduce hemorrhage and excessive bleeding, and emergency skills to manage prolonged labor.

This study found a higher percentage of stillbirths among mothers who used skilled assistance $(0.4 \%)$ compared with mothers who used UBA (0.3\%; Table 2). This might be related to childbirth complications, the first of the five major causes of stillbirth [20,21]. A high number of maternal complications at the time of birth may cause a high incidence of stillbirths among mothers who use skilled assistance at delivery.

This study found a higher proportion of neonatal deaths among mothers using UBA compared with those using skilled assistants at delivery. Similar findings have been reported in previous studies $[22,23]$. Neonatal infections account for about half of all neonatal deaths, and the leading causes of death are preterm birth complications, birth asphyxia, and poor obstetric care provided by unskilled birth assistants at delivery $[23,24]$. Although, there was no statistically significant association between type of assistance and neonatal death, the low proportion of deaths in newborn babies delivered by midwives showed better newborn care by midwives compared with unskilled birth assistants.

A previous study found that most midwives perform many tasks (including providing nutrition and immunizations) and attend few births, so their capacity to manage complications during childbirth and to recognize the need for referrals may be compromised because they encounter these situations infrequently [4]. Additionally, midwifery training focuses on normal births, which may restrict the midwife's capacity to manage complications during and after births. More importantly, there are substantial barriers to life-saving emergency obstetric care for home deliveries even when a midwife is present.

\section{Strengths and limitations of the study}

To our knowledge, this is the first reported study to evaluate the association between type of assistance at delivery and immediate outcomes for newborn babies and mothers following home delivery. Our findings raise doubts about the impact of skilled birth assistants, because there are substantial barriers to life-saving emergency obstetric care for home deliveries even when a midwife is present.

This study has some limitations. First, we used the IDBR51SV data from the DHS, which lacks information on maternal deaths during childbirth. Second, the exclusion of mothers who required medical 
doctors or nurses for delivery assistance might affect the generalizability of this study. However, the number of cases excluded was relatively small $(0.5 \%$ for medical doctors and $0.5 \%$ for nurses). Thus, our findings might be little affected by those exclusions. Third, the use of secondary data might have affected the validity of the findings because the data were primarily self-reported. However, the data have previously been used for research on a range of topics, and the quality of the data set had been maintained by ICF International [11]. Fourth, unknown confounding variables that were not assessed due to a lack of data, such as gestational age and birth weight of babies delivered at home, might explain why there was no statistically significant difference in neonatal mortality between mothers who used skilled assistants and those who received UBA. This might affect the generalizability of our findings to other countries.

\section{Conclusions}

This study confirmed that skilled birth assistants cannot mitigate adverse outcomes for home deliveries. The results suggest the need to monitor and assess the quality of care provided by midwives who assist with home deliveries. We suggest a comprehensive approach to improving the performance of midwives, such as clinical training using limited tool kits and a standard operating procedure (SOP) for managing complications during and after birth for home delivery assistants before midwives are placed in a village or rural area $[25,26]$. The skills of midwives included management of women and newborns with complications and referral to health facilities.

Acknowledging that midwives lack experience (compared with unskilled birth assistants) may be helpful. A subsequent study investigating maternal outcomes for recently graduated skilled birth assistants compared with those who have been practicing for longer might provide some insight as to how competency assessment influences outcomes.

\section{References:}

1. Ministry of Health, Government of Indonesia (1989) Directorate of Community Health.

2. Goverment of Indonesia, Ministary of Health (1998) The Indonesian translation of Central Agency on Statistics (BPS), \& National Family Planning Coordinating Board, Ministry of Health, ORC Macro. Indonesia Demographic and Health Survey 1997. Calverton, Maryland: BPS and ORC Macro.

3. Makowiecka K, Achadi E, Izati Y, Ronsmans C (2008) Midwifery provision in two districts in Indonesia: how well are rural areas served? Health Policy Plan 23: 67-75.

4. Ronsmans C, Scott S, Qomariyah SN, Achadi E, Braunholtz D, et al. (2009) Professional assistance during birth and maternal mortality in two Indonesian districts. Bull World Health Organ 87: 416-423.

5. Graham W, Bell J, Bullough C (2001) Can skilled attendance at delivery reduce maternal mortality in developing countries? Safe motherhood strategies: a review of the evidence. Studies in Health Services Organization and Policy 17: ITG Press: 97-130.

6. Singh K, Brodish P, Suchindran C (2014) A regional multilevel analysis: can skilled birth attendants uniformly decrease neonatal mortality? Matern Child Health J 18: 242-249.
7. Anand S, Bärnighausen T (2004) Human resources and health outcomes: cross-country econometric study. Lancet 364: 1603-1609.

8. McClure EM, Goldenberg RL, Bann CM (2007) Maternal mortality, stillbirth and measures of obstetric care in developing and developed countries. Int J Gynaecol Obstet 96: 139-146.

9. http://legacy.measuredhs.com/

10. Blondel B, Kogan MD, Alexander GR, Dattani N, Kramer MS, et al. (2002) The impact of the increasing number of multiple births on the rates of preterm birth and low birthweight: an international study. Am J Public Health 92: 1323-1330.

11. ICF International (2011) Demographic and Health Surveys Methodology - Questionnaires: Household, Woman's, and Man's. MEASURE DHS Phase III: Calverton, Maryland, USA.

12. Ronsmans C1, Graham WJ; Lancet Maternal Survival Series steering group (2006) Maternal mortality: who, when, where, and why. Lancet 368: 1189-1200.

13. 2012 World Health Organization, Newborn Care at Births.

14. Yakoob MY1, Lawn JE, Darmstadt GL, Bhutta ZA (2010) Stillbirths: epidemiology, evidence, and priorities for action. Semin Perinatol 34: 387-394.

15. Yakoob MY, Ali MA, Ali MU, Imdad A, Lawn JE, et al. (2011) The effect of providing skilled birth attendance and emergency obstetric care in preventing stillbirths. BMC Public Health 11 Suppl 3: S7.

16. Tinker A, ten Hoope-Bender P, Azfar S, Bustreo F, Bell R (2005) A continuum of care to save newborn lives. Lancet 365: 822-825.

17. Rothman KJ, Greenland S, Lash L Timothy (2008) Modern Epidemiology. Philadelphia, PA: Lippincott-Raven :51-69.

18. WHO (2004) Making pregnancy safer: the critical role of the skilled attendant: a joint statement by WHO, ICM and FIGO.

19. Heywood P, Harahap NP, Ratminah, M (2010) Current situation of midwives in Indonesia: Evidence from 3 districts in West Java Province. BMC Research Notes 3: 287.

20. Stillbirth Collaborative Research Network Writing Group1 (2011) Association between stillbirth and risk factors known at pregnancy confirmation. JAMA 306: 2469-2479.

21. Stillbirths-TheLancet.com (2011) An Executive Summary for The Lancet's Series. The lancet series.

22. Black RE, Cousens S, Johnson HL, Lawn JE, Rudan I, et al. (2010) Global, regional, and national causes of child mortality in 2008: a systematic analysis. Lancet 375: 1969-1987.

23. Hatt L, Stanton C, Makowiecka K, Adisasmita A, Achadi E, et al. (2007) Did the strategy of skilled attendance at birth reach the poor in Indonesia? Bull World Health Organ 85: 774-782.

24. Hatt L, Stanton C, Ronsmans C, Makowiecka K, Adisasmita A (2009) Did professional attendance at home births improve early neonatal survival in Indonesia? Health Policy Plan 24: 270-278.

25. Koblinsky M, Matthews Z, Hussein J, Mavalankar D, Mridha MK, et al. (2006) Going to scale with professional skilled care. Lancet 368: 1377-1386.

26. Darmstadt GL, Walker N, Lawn JE, Bhutta ZA, Haws RA, et al. (2008) Saving newborn lives in Asia and Africa: cost and impact of phased scaleup of interventions within the continuum of care. Health Policy Plan 23: 101-117. 